\title{
Transcatheter arterial chemoembolization in recurrent unresectable hepatocellular carcinoma after orthotopic liver transplantation
}

\author{
Hasmukh J. Prajapati', Pavan Kavali' ${ }^{2}$, Hyun S. Kim ${ }^{3,4}$ \\ ${ }^{I}$ Division of Interventional Radiology, Department of Pediatric Radiology, The University of Tennessee Health Science Center, Memphis, TN 38103, USA \\ ${ }^{2}$ Division of Interventional Radiology, Mallinckrodt Institute of Radiology, Washington University School of Medicine, St. Louis, MO 63110, USA. \\ ${ }^{3}$ Division of Interventional Radiology, Department of Radiology and Biomedical Imaging, Yale School of Medicine, New Haven, CT 06510, USA. \\ ${ }^{4}$ Yale Cancer Center, Yale School of Medicine, New Haven, CT 06510, USA.
}

Correspondence to: Dr. Hyun S. Kim, Yale Cancer Center, Yale School of Medicine, 330 Cedar Street, TE 2-224, New Haven, CT 06510, USA. E-mail: kevin.kim@yale.edu

How to cite this article: Prajapati HJ, Kavali P, Kim HS. Transcatheter arterial chemoembolization in recurrent unresectable hepatocellular carcinoma after orthotopic liver transplantation. Hepatoma Res 2017;3:182-8.

Article history:

Received: 19-06-2017

Accepted: 03-08-2017

Published: 17-08-2017

\section{Key words:}

Doxorubicin drug eluting

beads transcatheter arterial

chemoembolization,

recurrent hepatocellular

carcinoma,

orthotopic liver transplantation,

sorafenib,

alpha-fetoprotein

\begin{abstract}
Aim: To investigate the survivals and efficacy of the doxorubicin drug eluting beads transcatheter arterial chemoembolization (TACE) in patients with recurrent hepatocellular carcinoma (HCC) status post orthotopic liver transplantation. Methods: Consecutive patients with HCC who underwent orthotopic liver transplantation from 2005 to 2012 were reviewed. Patients who developed recurrent HCC after orthotopic liver transplantation and received doxorubicin drug eluting beads TACE therapy were identified and included in the study. Survivals were calculated from the time of 1 st doxorubicin drug eluting beads TACE of recurrent HCC. Kaplan Meier estimator with log rank test was used for survival analysis. Results: Eight patients had recurrent HCC after orthotopic liver transplantation and received doxorubicin drug eluting beads TACE. The overall median survival of these patients was 15.6 months. Two patients had significantly poorer overall median survival from doxorubicin drug eluting beads TACE (3.4 months) and both showed elevated serum alpha-fetoprotein levels $(>400 \mathrm{ng} / \mathrm{mL})$ and extra-hepatic metastases $(P=0.03)$. Patients with poorly differentiated HCC in explant liver had the poor median overall survival (3.6 months) compared to the patients with well-to-moderately differentiated HCC (21.7 months, $P=0.004)$. Conclusion: Doxorubicin drug eluting beads TACE appears to be an effective treatment option for patients with recurrent HCC after orthotopic liver transplantation.
\end{abstract}

\section{INTRODUCTION}

Hepatocellular carcinoma (HCC) is one of the leading cause of cancer related death globally. ${ }^{[1]}$ Among all the treatment options for HCC and cirrhosis, orthotopic liver transplantation (OLT) is considered the curative treatment option, especially for patients with endstage liver disease. Unfortunately, recurrence of HCC

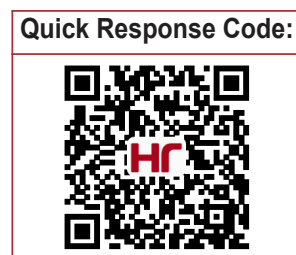


occurs after OLT..2] Many studies have reported on the patterns and prognostic factors for recurrence of HCC after liver transplantation. ${ }^{[3-6]}$ However, the reported prognostic factors investigated have been focused more on histopathologic and postoperative clinical data after HCC who did not receive chemoembolization. ${ }^{[3-6]}$ Several studies have been reported on the efficacy of conventional transcatheter arterial chemoembolization (cTACE) in recurrent HCC after OLT. ${ }^{[7,8]}$ Little is known about the survivals, efficacy and prognostic factors following doxorubicin drug eluting beads transcatheter arterial chemoembolization (DEB TACE) in patients with recurrent $\mathrm{HCC}$ status post OLT.

The purposes of this study were, first, to investigate the survivals and efficacy following DEB TACE in patients with recurrent HCC status post OLT and second, to identify the prognostic factors of survivals among these patients with recurrent tumors and to report the review of the literature.

\section{METHODS}

This is a single institutional retrospective analysis of prospective database with the patient's consent, approved by the Local Institutional Review Board and is Health Insurance Portability and Accountability Act compliant.

\section{Study objective}

The primary objective of the study was to assess the survivals and efficacy following DEB TACE in patients with recurrent HCC status post OLT. And the second objective was to identify the prognostic factors of survival among these patients with recurrent $\mathrm{HCC}$ after OLT who were treated with DEB TACE and to report the review of the literature on the similar studies.

\section{Patient selection}

There were 420 consecutive patients with unresectable HCC who received DEB TACE therapies from December 2005 to September 2012. A total of 56 patients underwent OLT after downstaging of HCC from DEB TACE. Patients who developed recurrent HCC after OLT were identified. Those patients who underwent DEB TACE for recurrent HCC were included in the study. A total of 8 patients met the inclusion criteria and included in the study. None of the HCC tumor was feasible for surgery or ablation treatment due to size or close proximity with liver capsule or hepatic vasculature. All patients had cirrhosis before OLT. One patient was alive at the end of the study. The patients who received treatment with sorafenib were also included in the study. All patients had an initial outpatient clinical evaluation, including pertinent medical and physical evaluations. The eastern cooperative oncology group (ECOG) performance status (PS) of each patient was documented before the DEB TACE procedure. The functional liver status was determined by using the Child-Pugh criteria. The American Association for the Study of Liver Disease-Journal of the National Cancer Institute guidelines ${ }^{[9]}$ were used to diagnose HCC. HCC was diagnosed if magnetic resonance imaging (MRI) showed a mass with the typical vascular pattern of arterial enhancement and portal venous "washout". For the index lesions between 1 and $2 \mathrm{~cm}$, two different studies were used to detect the typical pattern and for lesions $>2 \mathrm{~cm}$ in diameter, only one study was used. Here, index lesion means the largest lesion in the liver. Lesions with inconclusive features on imaging were biopsied for pathologic confirmation.

\section{DEB TACE procedure}

There were 18 DEB TACE procedures performed in 8 patients. The detail techniques of the procedure were mentioned elsewhere. ${ }^{[10]}$ The third or fourth order branches of feeding vessels supplying the tumor were catheterized with a $2.8 \mathrm{~F}$ (Renegade Hi-Flo; Boston Scientific, Natick, MA, USA) or a $2.1 \mathrm{~F}$ microcatheter (STC Renegade Hi-Flo; Boston Scientific, Natick, MA, USA). Then, the tumors were treated with a slow fluoroscopy-guided injection of iodinated contrast mixed 100-300 $\mu \mathrm{m}$ low compression beads impregnated with $50 \mathrm{mg}$ of doxorubicin in each vial. The first and second order branches of the right or left hepatic arteries were kept patent and documented on post-embolization completion angiogram. The endpoint for treatment included the administration of the 2 vials of DEB or sluggish flow in the subsegmental branches of the hepatic artery to the region of the tumor, without an effect on the flow in the main or lobar hepatic artery. After 2 vials of DEB TACE, no additional embolization was performed despite persistent high flow within the tumor.

\section{Follow-up}

Patients with large tumors of more than $5 \mathrm{~cm}$ or multifocal disease were re-treated in 4 weeks and the remainders of the patients were followed up in the clinic in 4 weeks with liver function tests and an MRI of the liver. Follow-up cross-sectional imaging was performed at 4 weeks from the last single or repeat DEB TACE treatment. Further treatments were based on clinical evaluation, laboratory values, and imaging response. If there was a progressive disease on follow up MRI at 4 weeks, then the patients were assessed for systemic therapy. Simultaneously, these patients were retreated with DEB TACE unless the disease progressed to the Barcelona-Clinic Liver Cancer D stage. If follow up MRI demonstrated residual or recurrent $\mathrm{HCC}$, then the patients were retreated with DEB TACE. If patients 
responded completely, then they were followed-up every 3-6 months with MRI.

\section{Statistical analysis}

Survivals were also stratified on the basis of age, gender, etiology, tumor burden, Okuda staging, ECOG PS, Child-Pugh class and Cancer of the Italian Liver Program staging. A $P$-value of 0.05 was held as significant. Survival was calculated from the time of first transcatheter therapy. The Kaplan-Meier method with the long rank test was used to estimate survival and difference. A patient was censored if he/she was alive at the end of the study period. SPSS software, version 21.0 (IBM, Somers, NY) was used to perform the statistical analyses.

\section{RESULTS}

\section{Patient population}

Eight patients had recurrence of HCC after OLT and received 18 DEB TACE treatments (range 1 to 4 ) after recurrence. The demographics, clinical, pathology and imaging characteristics of the patients are shown in Table 1. The mean age of the patients was 53.4 years (SD 4.6 years). The 5 patients had Child Pugh class A disease and 3 patients had Child Pugh class $B$ disease at the time of presentation of recurrent HCC. Cirrhosis was present in all patients, diagnosed by imaging. The 7 patients had hepatitis $C$ and 1 patient had hepatitis $\mathrm{B}$. The portal venous hypertension (PHT) was present in $50 \%$ of patients. The PHT was diagnosed on MRI. Clinically, ascites was present in 1 patient. The mean size of the index tumor was $3.3 \mathrm{~cm}$ (SD $0.85 \mathrm{~cm}$ ). Portal vein thrombosis or invasion was not present in any of the patients and extra-hepatic metastases were present in $25 \%$ of the patients ( $n$ $=2$ ) at the time of initial presentation. The 1 patient has T11 vertebral body metastasis and showed mildly increased activity on computed tomography (CT) positron emission tomography examination. The other patient had a single $9 \mathrm{~mm}$ lung metastasis on CT chest and it was surgically resected. These both patients had alpha-fetoprotein (AFP) of greater than $2,400 \mathrm{ng} / \mathrm{dL}$. During DEB TACE therapies, $25 \%(n=2)$ of patients received concurrent sorafenib systemic chemotherapy. The 6 patients (75\%) had solitary HCC and unilobar involvement after OLT. The 30-day mortality was zero.

\section{Survival analysis}

The overall median and mean survivals from the time of 1st DEB TACE were 15.6 and 19.6 months accordingly. The mean recurrence free survival from the time of OLT was 50.5 months. The mean survival from the time of the OLT was 72.1 months. One year and 2-year survivals from the time of 1 st DEB TACE were $62.5 \%(5 / 8)$ and $50 \%(4 / 8)$ respectively. The univariate survival analyses were performed for different categories as shown in Table 2. Two patients had significantly poor overall survivals from DEB TACE (3.27 and 3.4 months) as compared to other patients and both showed elevated serum AFP levels $(>2,400$ $\mathrm{ng} / \mathrm{mL}$ ) and extra-hepatic metastases [Table 2]. The

Table 1: Demographics, clinical, imaging, staging and survival characteristics of recurrent HCC patients after OLT treated with DEB TACE

\begin{tabular}{|c|c|c|c|c|c|c|c|c|}
\hline Variables & P 1 & P 2 & P 3 & P 4 & P 5 & P 6 & P 7 & P 8 \\
\hline Age (years) & 51.7 & 44.5 & 54.0 & 59.5 & 55.0 & 51.4 & 52.7 & 58.3 \\
\hline Living status & Alive & Dead & Dead & Dead & Dead & Dead & Dead & Dead \\
\hline Gender & Male & Male & Male & Male & Male & Male & Female & Female \\
\hline Race & White & Other & White & White & White & Black & White & Other \\
\hline Etiology & Hepatitis C & Hepatitis B & Hepatitis C & Hepatitis C & Hepatitis C & Hepatitis C & Hepatitis C & Hepatitis C \\
\hline Index tumor size $(\mathrm{cm})$ & 2.2 & 2.2 & 2.8 & 3.1 & 3.3 & 3.9 & 4.1 & 4.7 \\
\hline Number of the tumor & 1 & 12 & 1 & 9 & 1 & 1 & 1 & 1 \\
\hline $\begin{array}{l}\text { Histology grading of the } \\
\text { explant liver HCC }\end{array}$ & $\begin{array}{c}\text { Well or } \\
\text { moderately } \\
\text { differentiated }\end{array}$ & $\begin{array}{c}\text { Poorly } \\
\text { differentiated }\end{array}$ & $\begin{array}{c}\text { Poorly } \\
\text { differentiated }\end{array}$ & $\begin{array}{c}\text { Well or } \\
\text { moderately } \\
\text { differentiated }\end{array}$ & $\begin{array}{c}\text { Well or } \\
\text { moderately } \\
\text { differentiated }\end{array}$ & $\begin{array}{c}\text { Well or } \\
\text { moderately } \\
\text { differentiated }\end{array}$ & $\begin{array}{c}\text { Well or } \\
\text { moderately } \\
\text { differentiated }\end{array}$ & $\begin{array}{c}\text { Well or } \\
\text { moderately } \\
\text { differentiated }\end{array}$ \\
\hline $\begin{array}{l}\text { Metastases at time } \\
\text { of recurrent HCC } \\
\text { presentation before DEB } \\
\text { TACE }\end{array}$ & No & Yes & No & No & No & Yes & No & No \\
\hline $\begin{array}{l}\text { Alfa-fetoprotein }(\mathrm{ng} / \mathrm{dL}) \text { of } \\
\text { recurrent HCC }\end{array}$ & 5 & $>2,400$ & $<5$ & 10.6 & 11.8 & $>2,400$ & 40.9 & 9.8 \\
\hline $\begin{array}{l}\text { Child-Pugh class of } \\
\text { recurrent HCC }\end{array}$ & A & B & A & A & B & A & A & B \\
\hline $\begin{array}{l}\text { Tumor free survivals from } \\
\text { OLT (months) }\end{array}$ & 32.9 & 25 & 13.7 & 83.1 & 117 & 40.3 & 28.4 & 63.6 \\
\hline $\begin{array}{l}\text { Concurrent sorafenib } \\
\text { treatment }\end{array}$ & No & Yes & No & No & No & Yes & No & No \\
\hline
\end{tabular}

P: patient number; DEB TACE: doxorubicin drug eluting beads transcatheter arterial chemoembolization; OLT: orthotopic liver transplantation; HCC: hepatocellular carcinoma 
shortest survival from DEB TACE was 3.4 months and the patient had hepatitis $B$ and more than $12 \mathrm{HCC}$ tumors with extra-hepatic metastasis and AFP > 2,400 $\mathrm{ng} / \mathrm{mL}$. Survival curves generated by Kaplan Meier analysis according to the status of AFP and metastases are shown in the Figure $1 \mathrm{~A}$ and $\mathrm{B}$. The histology grading of HCCs of the explant liver was correlated with the survivals. The patients with poorly differentiated HCC had the poor overall survivals (3.4 months) compared

Table 2: Median survivals (from 1st DEB TACE) HCC patients after OLT treated with DEB TACE

\begin{tabular}{|c|c|c|c|}
\hline Demographics & $\begin{array}{l}\text { Number of } \\
\text { patients }\end{array}$ & $\begin{array}{l}\text { Median survival } \\
\text { (months) }\end{array}$ & $\begin{array}{c}P \\
\text { value }\end{array}$ \\
\hline Total number of patients & 8 & 15.6 & \\
\hline \multicolumn{4}{|l|}{ Child-Pugh class } \\
\hline A & 5 & 21.7 & \multirow[t]{2}{*}{0.45} \\
\hline $\mathrm{B}$ & 3 & 15.6 & \\
\hline \multicolumn{4}{|l|}{ Okuda staging } \\
\hline I & 6 & 9.3 & \multirow[t]{2}{*}{0.9} \\
\hline II & 2 & 15.6 & \\
\hline \multicolumn{4}{|l|}{ CLIP staging } \\
\hline Early & 3 & 39.4 & \multirow[b]{2}{*}{0.2} \\
\hline Intermediate & 5 & 15.6 & \\
\hline \multicolumn{4}{|l|}{ ECOG performance status } \\
\hline 0 & 4 & 39.4 & \multirow{3}{*}{0.3} \\
\hline 1 & 3 & 21.7 & \\
\hline 2 & 1 & 7.7 & \\
\hline \multicolumn{4}{|l|}{ Imaging findings } \\
\hline Ascites & & & \\
\hline Present & 1 & 26.8 & \multirow[t]{2}{*}{0.7} \\
\hline Absent & 7 & 15.6 & \\
\hline \multicolumn{4}{|l|}{ Portal hypertension } \\
\hline Present & 4 & 7.8 & \multirow[t]{2}{*}{0.2} \\
\hline Absent & 4 & 21.7 & \\
\hline \multicolumn{4}{|l|}{ Tumor morphology } \\
\hline \multicolumn{4}{|l|}{ Tumor locations } \\
\hline Unilobar & 6 & 15.6 & \multirow[t]{2}{*}{0.27} \\
\hline Bilobar & 2 & 3.4 & \\
\hline \multicolumn{4}{|l|}{ Number of tumors } \\
\hline Solitary & 6 & 15.6 & \multirow[t]{2}{*}{0.14} \\
\hline Multiple & 2 & 3.4 & \\
\hline \multicolumn{4}{|l|}{ Size of index tumor } \\
\hline$<3 \mathrm{~cm}$ & 6 & 15.6 & \multirow[b]{2}{*}{0.87} \\
\hline $3 \mathrm{~cm}$ or more & 2 & 7.8 & \\
\hline \multicolumn{4}{|l|}{ Extrahepatic metastasis } \\
\hline Present & 2 & 3.4 & \multirow[t]{2}{*}{0.03} \\
\hline Absent & 6 & 21.7 & \\
\hline \multicolumn{4}{|l|}{ Laboratory data } \\
\hline \multicolumn{4}{|c|}{ Serum alpha-fetoprotein level (ng/dL) of recurrent HCC } \\
\hline$<400$ & 6 & 21.7 & \multirow[t]{2}{*}{0.03} \\
\hline$\geq 400$ & 2 & 3.4 & \\
\hline \multicolumn{4}{|c|}{ Histology grading of the explant liver HCC } \\
\hline $\begin{array}{l}\text { Well or moderately } \\
\text { differentiated }\end{array}$ & 6 & 21.7 & \multirow[t]{2}{*}{0.004} \\
\hline Poorly differentiated & 2 & 3.6 & \\
\hline
\end{tabular}

HCC: hepatocellular carcinoma; DEB TACE: doxorubicin drug eluting beads transcatheter arterial chemoembolization; OLT: orthotopic liver transplantation; CLIP: Cancer of the Italian Liver Program; ECOG: eastern cooperative oncology group
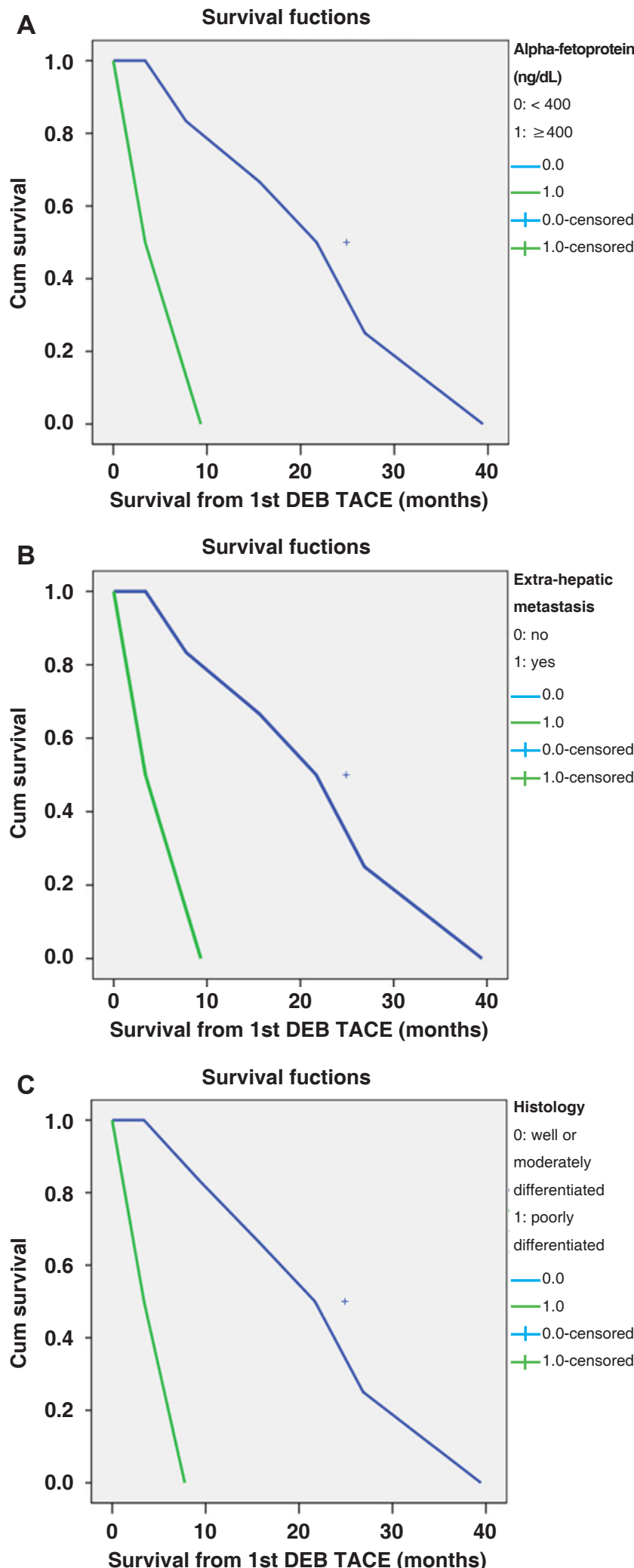

Figure 1: Survival curves generated by Kaplan Meier analysis according to the status of alpha-fetoprotein level $(A)$, presence or absence of the extra-hepatic metastasis (B) and histology grading of the explant liver $(C)$ before DEB TACE in patient with recurrent HCC after orthotopic liver transplantation. HCC: hepatocellular carcinoma; DEB TACE: doxorubicin drug eluting beads transcatheter arterial chemoembolization 
to the patients with well or moderately differentiated HCC of the explant liver (21.7 months, $P=0.004)$. The survival curve generated by Kaplan Meier analysis according to the status of histology grading of the explant liver is shown in the Figure 1C. Although, there was a survival difference in the patients between Child A and B disease, statistically it was found nonsignificant. This can likely be due to small sample size. In this study, 25\% patients received concurrent treatment with sorafenib with a median survival of 7.7 months compared to a median survival of 21.7 months in patients who did not receive sorafenib $(P=0.19)$.

\section{DISCUSSION}

Recurrence of HCC after liver transplantation has a major effect on reducing patient's overall survival. ${ }^{[11]}$ In general, all treatment options currently available for advanced HCC are also potentially feasible after OLT. Treatments include resection, ablation, transarterial embolization or radioembolization, and systemic treatment with sorafenib. The 5-year posttransplant survival was $47 \%$ for patients who underwent surgical resection to treat recurrence. ${ }^{[11]}$ The ability for surgical treatment and a late onset ( $>24$ months) of recurrence are factors associated with long-term survival. ${ }^{[12]}$ Local ablative techniques, such as radiofrequency ablation, cryoablation, or percutaneous ethanol ablation, also yield favorable survival outcomes in patients with small unresectable recurrent HCC. ${ }^{[13,14]}$ In our study, none of the HCC tumor was feasible for surgery or ablation treatment due to size or close proximity with liver capsule or hepatic vasculature. All patients had cirrhosis before OLT. In 2007, sorafenib was the first agent to demonstrate a significant improvement in the overall survival of patients with advanced HCC. ${ }^{[15,16]}$ The survival benefits from sorafenib ranged from 2 to 3 months in advanced HCC patients. ${ }^{[15,16]}$ Since these two landmark studies, saorafenib has become the standard of care for advanced HCC patients. It has also shown improved survival benefits in patients with recurrent HCC after OLT as compared to best supportive care. ${ }^{[17]}$ Yittrium-90 radioembolization has shown benefits in HCC patients. ${ }^{[18]}$ However, no specific radioembolization study was found in patients with recurrence of HCC after OLT.

DEB TACE is a well-known locoregional treatment for HCC evaluated by multiple randomized controlled studies. Recently, numerous studies have been reported favorable outcomes with the use of DEB TACE for HCC. ${ }^{[10,19-22]}$ DEB TACE has demonstrated improved survival, better tolerability, and fewer side effects as compared to conventional TACE. ${ }^{[19,21-23]}$ In these reported DEB TACE studies, the survivals in patients with unresectable HCC, ranged from 13.5 to 24.5 months. ${ }^{[10,19-22]}$ In the current study, the overall median and mean survivals from the time of 1st DEB TACE were 15.6 and 19.6 months accordingly, which is comparable with the reported DEB TACE studies.

Little is known on the survivals, efficacy and prognostic factors of survivals following DEB TACE in patients with recurrent HCC status post OLT. Few similar studies were found from English literature. ${ }^{[7,8]}$ Zhou et al. ${ }^{[7]}$ reported that conventional TACE is safe following in patients with recurrent HCC status post OLT. Their study indicated that TACE treatment seems to produce an effective tumor response for targeted recurrent $\mathrm{HCC}$ after liver transplantation. The Child Pugh Class of HCC patient is considered to be the one of the main prognostic factors for survival following TACE in HCC patients. ${ }^{[24-26]}$ In our study, there was a survival difference in the patients between Child $A$ and $B$ disease. However, statistically it was found nonsignificant. This can likely be due to small sample size.

Recurrence of HCC ranged from $10 \%$ to as high as $40 \%{ }^{[2,27,28]}$ Therefore, surveillance with MRI of the abdomen is very important in these patients. Patients with early recurrence had much worse overall survival than those with late recurrence. ${ }^{[2,27,28]}$ In our studies, 2 patients had shortest tumor free survival of 13.3 and 25 months and had worst overall median survivals of 3.4 and 7.7 months respectively. Both patients had poorly differentiated HCC of the explant liver. The patients with poorly differentiated HCC had the poor overall survivals (3.4 months) compared to the patients with well to moderately differentiated HCC of the explant liver (21.7 months, $P=0.004)$. A histological grade of $\mathrm{HCC}$ is an important prognostic factor affecting patient survival after OLT. The importance of the grade of the histology of the explant liver HCC in patient's prognosis has previously reported. ${ }^{[5,6,29]}$

The prognostic factors for poor survivals other than the histology grading, the number and size of the tumors have been reported by many investigators. These factors include microscopic vascular invasion by the $\mathrm{HCC},{ }^{[30,31]}$ presence of partial necrosis of the nodule in the explanted specimen, ${ }^{[32]}$ presence of microscopic satellite nodules in the explanted specimen, ${ }^{[33]}$ specific type of lymphocytic infiltrate to the tumor as immune response, ${ }^{[34]}$ high preoperative level of serum AFP, ${ }^{[35]}$ and advanced tumour-node-metastasis stage and extra-hepatic metastases. ${ }^{[4,5]}$ In this study, 2 patients had elevated AFP and extra-hepatic metastases had the poorest survivals. As these facts help in identifying the patients who will get the most benefit from the DEB TACE treatment. 
We acknowledge, this study has several limitations. First, the sample size of the study is small and so results should be taken as preliminary data. Second, this is a single institution non-randomized study, so selection bias and late look bias may be inherent. Third, patients who were treated with sorafenib $(25 \%)$ were also included in this study, so outcomes after DEB TACE may be confounded. However, concomitant therapy with sorafenib did not significantly affect survival in univariate analysis. Therefore, we believe that survival advantage in this study is largely from the effect of DEB TACE therapy.

In conclusion, recurrence of HCC after OLT is not uncommon. DEB TACE could help to extend the survival of the patients with recurrent HCC after OLT. As the sample size of the study is small, the results should be taken as preliminary. Further, multiinstitutional prospective trial is needed to explore its benefit on these patients with recurrence of HCC after OLT. Patients with poorly differentiated HCC of explant liver, $>400 \mathrm{ng} / \mathrm{dL}$ AFP and metastases at the time of TACE had a poor overall prognosis.

\section{DECLARATIONS}

\section{Authors' contributions}

All three authors were involved with study concept, design, acquisition of data, analysis and interpretation of data, drafting of the manuscript and critical revision of the manuscript for important intellectual content.

\section{Financial support and sponsorship}

None.

\section{Conflicts of interest}

There are no conflicts of interest.

\section{Patient consent}

Obtained.

\section{Ethics approval}

The study is approved by the Local Institutional Review Board and is Health Insurance Portability and Accountability Act compliant.

\section{REFERENCES}

1. Parkin DM, Bray F, Ferlay J, Pisani P. Global cancer statistics, 2002. CA Cancer J Clin 2005;55:74-108.

2. Kurtovic J, Riordan SM, Williams R. Liver transplantation for hepatocellular carcinoma. Best Pract Res Clin Gastroenterol 2005; 19:147-60.

3. Jonas S, Bechstein WO, Steinmuller T, Herrmann M, Radke C, Berg $\mathrm{T}$, Settmacher U, Neuhaus P. Vascular invasion and histopathologic grading determine outcome after liver transplantation for hepatocellular carcinoma in cirrhosis. Hepatology 2001;33:1080-6.

4. Ferris JV, Baron RL, Marsh JW Jr, Oliver JH 3rd, Carr BI, Dodd GD 3rd. Recurrent hepatocellular carcinoma after liver transplantation: spectrum of CT findings and recurrence patterns. Radiology 1996;198:233-8

5. Peck-Radosavljevic M, Pidlich J, Bergmann M, Ferenci P, Seelos C, Wichlas M, Lipinski E, Gnant M, Gangl A, Muhlbacher F. Preoperative TNM-classification is a better prognostic indicator for recurrence of hepatocellular carcinoma after liver transplantation than albumin mRNA in peripheral blood. Liver Transplant Oncology Group. J Hepatol 1998;28:497-503.

6. Dudek K, Kornasiewicz O, Remiszewski P, Kobryn K, ZiarkiewiczWroblewska B, Gornicka B, Zieniewicz K, Krawczyk M. Impact of tumor characteristic on the outcome of liver transplantation in patients with hepatocellular carcinoma. Transplant Proc 2009;41:3135-7.

7. Zhou B, Shan H, Zhu KS, Jiang ZB, Guan SH, Meng XC, Zeng XC. Chemoembolization with lobaplatin mixed with iodized oil for unresectable recurrent hepatocellular carcinoma after orthotopic liver transplantation. J Vasc Interv Radiol 2010;21:333-8.

8. Yamagami T, Yoshimatsu R, Ishikawa M, Kajiwara K, Aikata H, Tashiro H, Kakizawa H, Toyoda N, Ohdan H, Awai K. Transcatheter arterial chemoembolization with an interventional-CT system for recurrent hepatocellular carcinoma after living donor liver transplantation. Hepatogastroenterology 2014;61:1387-92.

9. Bruix J, Sherman M. Management of hepatocellular carcinoma. Hepatology 2005;42:1208-36.

10. Prajapati HJ, Dhanasekaran R, El-Rayes BF, Kauh JS, Maithel SK, Chen Z, Kim HS. Safety and efficacy of doxorubicin drug-eluting bead transarterial chemoembolization in patients with advanced hepatocellular carcinoma. $J$ Vasc Interv Radiol 2013;24:307-15.

11. Roayaie S, Schwartz JD, Sung MW, Emre SH, Miller CM, Gondolesi GE, Krieger NR, Schwartz ME. Recurrence of hepatocellular carcinoma after liver transplant: patterns and prognosis. Liver Transpl 2004; 10:534-40

12. Kornberg A, Kupper B, Tannapfel A, Katenkamp K, Thrum $\mathrm{K}$, Habrecht $\mathrm{O}$, Wilberg J. Long-term survival after recurrent hepatocellular carcinoma in liver transplant patients: clinical patterns and outcome variables. Eur J Surg Oncol 2010;36:275-80.

13. Orlando A, Leandro G, Olivo M, Andriulli A, Cottone M. Radiofrequency thermal ablation vs. percutaneous ethanol injection for small hepatocellular carcinoma in cirrhosis: meta-analysis of randomized controlled trials. Am J Gastroenterol 2009;104:514-24.

14. Shiina S. Image-guided percutaneous ablation therapies for hepatocellular carcinoma. J Gastroenterol 2009;44 Suppl 19:122-31.

15. Cheng AL, Kang YK, Chen Z, Tsao CJ, Qin S, Kim JS, Luo R, Feng J, Ye S, Yang TS, Xu J, Sun Y, Liang H, Liu J, Wang J, Tak WY, Pan H, Burock K, Zou J, Voliotis D, Guan Z. Efficacy and safety of sorafenib in patients in the Asia-Pacific region with advanced hepatocellular carcinoma: a phase III randomised, double-blind, placebo-controlled trial. Lancet Oncol 2009;10:25-34.

16. Llovet JM, Ricci S, Mazzaferro V, Hilgard P, Gane E, Blanc JF, de Oliveira AC, Santoro A, Raoul JL, Forner A, Schwartz M, Porta C, Zeuzem S, Bolondi L, Greten TF, Galle PR, Seitz JF, Borbath I, Haussinger D, Giannaris T, Shan M, Moscovici M, Voliotis D, Bruix $\mathrm{J}$, Group SIS. Sorafenib in advanced hepatocellular carcinoma. $N$ Engl J Med 2008:359:378-90

17. Sposito C, Mariani L, Germini A, Flores Reyes M, Bongini M, Grossi G, Bhoori S, Mazzaferro V. Comparative efficacy of sorafenib versus best supportive care in recurrent hepatocellular carcinoma after liver transplantation: a case-control study. J Hepatol 2013;59:59-66.

18. Salem R, Lewandowski RJ, Mulcahy MF, Riaz A, Ryu RK, Ibrahim S, Atassi B, Baker T, Gates V, Miller FH, Sato KT, Wang E, Gupta $\mathrm{R}$, Benson AB, Newman SB, Omary RA, Abecassis M, Kulik L. 
Radioembolization for hepatocellular carcinoma using Yttrium-90 microspheres: a comprehensive report of long-term outcomes. Gastroenterology 2010;138:52-64.

19. Sacco R, Bargellini I, Bertini M, Bozzi E, Romano A, Petruzzi P, Tumino E, Ginanni B, Federici G, Cioni R, Metrangolo S, Bertoni M, Bresci G, Parisi G, Altomare E, Capria A, Bartolozzi C. Conventional versus doxorubicin-eluting bead transarterial chemoembolization for hepatocellular carcinoma. J Vasc Interv Radiol 2011;22:1545-52.

20. Padia SA, Shivaram G, Bastawrous S, Bhargava P, Vo NJ, Vaidya S, Valji K, Harris WP, Hippe DS, Kogut MJ. Safety and efficacy of drug-eluting bead chemoembolization for hepatocellular carcinoma: comparison of small-versus medium-size particles. J Vasc Interv Radiol 2013;24:301-6.

21. Malagari K, Chatzimichael K, Alexopoulou E, Kelekis A, Hall B, Dourakis S, Delis S, Gouliamos A, Kelekis D. Transarterial chemoembolization of unresectable hepatocellular carcinoma with drug eluting beads: results of an open-label study of 62 patients. Cardiovasc Intervent Radiol 2008;31:269-80.

22. Lammer J, Malagari K, Vogl T, Pilleul F, Denys A, Watkinson A, Pitton M, Sergent G, Pfammatter T, Terraz S, Benhamou Y, Avajon Y, Gruenberger T, Pomoni M, Langenberger H, Schuchmann M, Dumortier J, Mueller C, Chevallier P, Lencioni R. Prospective randomized study of doxorubicin-eluting-bead embolization in the treatment of hepatocellular carcinoma: results of the PRECISION V study. Cardiovasc Intervent Radiol 2010;33:41-52.

23. Dhanasekaran R, Kooby DA, Staley CA, Kauh JS, Khanna V, Kim HS. Comparison of conventional transarterial chemoembolization (TACE) and chemoembolization with doxorubicin drug eluting beads (DEB) for unresectable hepatocelluar carcinoma (HCC). J Surg Oncol 2010;101:476-80.

24. Hu HT, Kim JH, Lee LS, Kim KA, Ko GY, Yoon HK, Sung KB, Gwon DI, Shin JH, Song HY. Chemoembolization for hepatocellular carcinoma: multivariate analysis of predicting factors for tumor response and survival in a 362-patient cohort. J Vasc Interv Radiol 2011;22:917-23.

25. Huo TI, Hsu CY, Huang YH, Su CW, Lin HC, Lee RC, Chiou YY, Chiang JH, Lee PC, Lee SD. Prognostic prediction across a gradient of total tumor volume in patients with hepatocellular carcinoma undergoing locoregional therapy. BMC Gastroenterol 2010;10:146.

26. Sellers MT, Huggins S, Kegley K, Pollinger HS, Shrestha R, Johnson MW, Stein LL, Panjala C, Tan M, Arepally A, Jacobs L,
Caldwell C, Bosley M, Citron SJ. Multivariate analysis of prognostic factors for survival following doxorubicin-eluting bead transarterial chemoembolization for hepatocellular carcinoma. J Vasc Interv Radiol 2013;24:647-54.

27. Besnard M, Fauchon G, Thomassin C, Gerard JL, Locker B, Bricard H. Efficacy and tolerance of Elohes 6\% during peroperative normovolemic dilution. Ann Fr Anesth Reanim 1992;11:531-3. (in French)

28. Regalia E, Coppa J, Pulvirenti A, Romito R, Schiavo M, Burgoa L, Mazzaferro V. Liver transplantation for small hepatocellular carcinoma in cirrhosis: analysis of our experience. Transplant Proc 2001;33:1442-4

29. Tamura S, Kato T, Berho M, Misiakos EP, O'Brien C, Reddy KR, Nery JR, Burke GW, Schiff ER, Miller J, Tzakis AG. Impact of histological grade of hepatocellular carcinoma on the outcome of liver transplantation. Arch Surg 2001;136:25-30; discussion 31

30. Salizzoni M, Romagnoli R, Lupo F, David E, Mirabella S, Cerutti E Ottobrelli A. Microscopic vascular invasion detected by anti-CD34 immunohistochemistry as a predictor of recurrence of hepatocellular carcinoma after liver transplantation. Transplantation 2003;76:844-8.

31. Lee HH, Joh JW, Park JH, Lee KW, Heo JS, Choi SH, Kim SJ, Lee SK. Microvascular tumor embolism: independent prognostic factor after liver transplantation in hepatocellular carcinoma. Transplant Proc 2005;37:1251-3.

32. Ravaioli M, Grazi GL, Ercolani G, Fiorentino M, Cescon M, Golfier R, Trevisani F, Grigioni WF, Bolondi L, Pinna AD. Partial necrosis on hepatocellular carcinoma nodules facilitates tumor recurrence after liver transplantation. Transplantation 2004;78:1780-6.

33. Plessier A, Codes L, Consigny Y, Sommacale D, Dondero F, Cortes A, Degos F, Brillet PY, Vilgrain V, Paradis V, Belghiti J, Durand F. Underestimation of the influence of satellite nodules as a risk factor for post-transplantation recurrence in patients with small hepatocellular carcinoma. Liver Transpl 2004;10:S86-90.

34. Unitt E, Marshall A, Gelson W, Rushbrook SM, Davies S, Vowler SL, Morris LS, Coleman N, Alexander GJ. Tumour lymphocytic infiltrate and recurrence of hepatocellular carcinoma following liver transplantation. J Hepatol 2006;45:246-53.

35. Ravaioli M, Ercolani G, Cescon M, Vetrone G, Voci C, Grigioni WF D'Errico A, Ballardini G, Cavallari A, Grazi GL. Liver transplantation for hepatocellular carcinoma: further considerations on selection criteria. Liver Transpl 2004;10:1195-202. 